\title{
Serum progesterone assay: a most sensitive marker for a failing pregnancy
}

\begin{abstract}
The common practice of using a single serum progesterone value to predict the outcome of a pregnancy in its early stages is flawed. Much has been written about the predictive value of a single serum progesterone value of $20 \mathrm{nmol} / 1(6.2 \mathrm{ng} / \mathrm{ml})$. Our case reveals that a single serum progesterone value may not be as sensitive in predicting a pregnancy outcome as the trend in two successive values.

Compared to the more widely used serum Beta hcg; the serum progesterone trend is more sensitive, results in an opportunity for earlier interpretation of the data and more focused management plans and is no more expensive than the more commonly used serum beta hcg.
\end{abstract}

Volume 8 Issue I - 2018

\author{
Harris E Phillip, Safwat Tosson \\ Obstetrician and Gynaecology consultants, Gibraltar
}

Correspondence: Harris E Phillip, Obstetrician and Gynaecology consultants, Gibraltar,

Email burns@doctors.org.uk

Received: January 09, 2018| Published: February 05, 2018

\section{Case report}

A 26year-old, Gravida 3 para $1+1$ patient presented to the accident and emergency department with a positive urine pregnancy test. A serum beta-hcg was taken and the patient was examined but found to have no clinical signs of an ectopic pregnancy. She was discharged and advised to return in 48 hours for a repeat serum beta hcg. The value of her serum beta-hcg on presentation on August 4, 2015 was $843.1 \mathrm{miu} / \mathrm{ml}$, a repeat 48 hours later was $1876 \mathrm{miu} / \mathrm{ml}$, an increase of in excess of $122 \%$. A serum progesterone on August 4 was also requested and the value was $52.9 \mathrm{nmol} / \mathrm{Ll}$. Interestingly a repeat serum progesterone 48 hours later showed a decline in serum progesterone to $47.34 \mathrm{nmol} / \mathrm{L}$, surely this is not in keeping with normal physiology. A repeat serum beta hcg 7 days later on the $15 / 08 / 15$ was $11,809 \mathrm{miu} /$ $\mathrm{ml}$ whereas the serum progesterone was $37.26 \mathrm{nmol} / \mathrm{L}$. The patient had both a transabdominal and transvaginal scan on the 15/08/2015 and an empty uterus with a prominent endometrial reaction was identified, at the time the patient had little mild lower abdominal pains and no free fluid in the pouch of Douglas.

The following morning on the $16 / 08 / 2015$, the patient was pain free and she had a repeat abdominal and transvaginal scan which again revealed an empty uterus with a less prominent endometrial reaction, a left sided complex mass and no free fluid in the Pouch of Douglas. Dark blood was noted on the transvaginal probe, although the patient did not complain of any vaginal loss.

In light of the findings on ultrasound scan, the patient's bloods namely, her serum beta-hcg and progesterone levels were repeated, this revealed a beta-hcg of $9220 \mathrm{miu} / \mathrm{ml}$, a drop of about $22 \%$ in less than 24 hours and a further decline in serum progesterone to $27.890 \mathrm{nmol} / \mathrm{L}$. A diagnostic laparoscopy was performed. At laparoscopy, there was a $2 \mathrm{~cm}$ by $3 \mathrm{~cm}$ left ampullary ectopic gestation; there was no free fluid in the pouch of Douglas. The patient had a laparoscopic left salpingectomy and she was discharged home the following day.

\section{Discussion}

Progesterone, a hormone, is thought to play a crucial role in the maintenance of pregnancy. In early stages of pregnancy, the corpus luteum (yellow body) is thought to be its primary source. This role is eventually assumed by the placenta as the embryo/foetus develops. It would therefore seem that for a developing pregnancy to be sustained, the progesterone titres should increases the pregnancy progresses. We were therefore concerned by the declining serum progesterone levels in an early pregnancy despite a continuing rise in the serum beta-hcg values beyond the critical $66 \%$ levels expected within 48 hours. It is noted that the National Institute of Clinical Excellence (NICE) does not recommend the simultaneous use of serum beta hcg and serum progesterone in the management of a pregnancy of unknown location. This clinical scenario, however, may suggest that the declining serum progesterone levels are a more sensitive marker of a failing pregnancy than serial serum beta-hcg values. Simultaneously, It will be noted that a single progesterone value as an indicator of foetal wellbeing could be misleading. Contrary to Mc Cond ML who contends that a serum progesterone greater than $50 \mathrm{nmol} / \mathrm{L}$ tends to be found in a viable pregnancy.

The serum progesterone value that is regularly quoted to suggest foetal wellbeing is a value greater than $50 \mathrm{nmol} / \mathrm{Ll}$, in our case the first recorded serum progesterone level was $52.9 \mathrm{nmol} / \mathrm{L}$. This had the effect of providing the clinician with false reassurance and gave him a tool which could have been used to inadvertently misguide the patient. Interestingly, repeating the serum progesterone in 48 hours revealed a decline in the serum progesterone levels. In our patient, it will also be noted that whilst the serum beta hcg value continued to rise even some ten days after the initial contact with the first recorded decline at day 11 from presentation, the progesterone level never fluctuated but showed a continuous decline. This, though a single case, a declining serum progesterone level is probably a more sensitive marker for a failing pregnancy than serial serum b-hcg. It also strongly suggests that the $66 \%$ or greater increase of the serum beta-hcg over 48 hours is not as sensitive as previously thought in ruling out a failing pregnancy. In our case the serum beta hcg increased in excess of $122 \%$ within 48 hours of presentation. Caution is therefore advised in the interpretation of a $66 \%$ or greater rise in serum b-hcg within a 48 hour epoch.

We recognise that this is a case report with its known inherent weaknesses and we are reluctant in making strong claims for the preference of repeat progesterone assays over serial serum beta-hcg in assessing foetal wellbeing. We are, however, left to ponder whether a decline in the serum progesterone titre which can be realised as early as 24 hours from the initial assay is not a sufficiently sensitive biomarker 
to predict pregnancy outcome and therefore may provide clinicians with a useful tool in both counselling and informing patient's care.

The more widely used practice of serial serum beta hcgtiters may be much less sensitive and the difference in cost is a negligible 5pence (cost of kit progesterone £3.12, labour £3.18, total: $£ 6.30$; for serum beta hcg: cost of kit :3.07, labour $£ 3.18$ cost £6.25). Yet the use of progesterone assay as a marker for a failing pregnancy has been virtually replaced by the serum beta hcgtiters. This case report suggests that the decline is sufficiently rapid to allow the successive assays to be done at 24 hour intervals. It simultaneously destroys the previously held view that much about foetal wellbeing is gained from a single serum progesterone value. The trend between successive assays is arguably a stronger predictor of foetal status. ${ }^{1-5}$

\section{Acknowledgements}

None.

\section{Conflict of interest}

The author declares no conflict of interest.

\section{Referecnes}

1. Yeko TR, Gorrill MJ, Hughes LH, et al. Timely diagnosis of early ectopic pregnancy using a single blood progesterone measurement. Fertil Steril. 1987;48(6):1048-1050.

2. Stovall TG, Ling FW, Cope BJ, et al. Preventing ruptured ectopic pregnancy with a single serum progesterone. AMJ Obstetric Gynaecol. 1989;160(6):1425-1431

3. Peterson CM, Kreger D, Delgado P, et al. Laboratory and clinical comparison of a rapid versus a classic progesterone radioimmunoassay for use in determining abnormal and ectopic pregnancies. Am J Obstet Gynecol. 1992;166(2):562-566.

4. https://www.nice.org.uk/search?q=Serum+progesterone

5. Jorine Verhaegen, ID Gallos, NM van Mello, et al. Accuracy of single progesterone test to predict early pregnancy outcome in women with pain or bleeding: meta-analysis of cohort studies. BMJ. 2012. 